\title{
Desafios da gestão democrática: uma análise do sistema escolar de tempo integral de Manaus
}

\author{
Challenges of democratic management: an analysis of the Manaus \\ integral time school system
}

\section{Desafíos de la gestión democrática: un análisis del sistema escolar de tiempo completo de Manaus}

\section{Cintia Adélia da Silva'}

Fundação Universidade Federal de Rondônia, Grupo de Pesquisa Centro Interdisciplinar de Estudos e Pesquisas em Educação e Sustentabilidade, Pesquisadora.

https://orcid.org/0000-0002-7455-9814

\section{Arminda Rachel Botelho Mourão²}

Universidade Federal do Amazonas, Programa Stricto Sensu em Educação e Doutorado em Educação, Professora Titular. https://orcid.org/0000-0002-1940-9477

Resumo: No estado do Amazonas, o sistema de educação integral está constituído por dois subsistemas: um, das Escolas Estaduais de Tempo Integral - EETls e, outro, dos Centros Estaduais de Tempo Integral - CETls. Este artigo resulta de uma pesquisa realizada, em 2014, em três Escolas Estaduais de Tempo Integral - EETls, com o objetivo de verificar em que condições de trabalho, a práxis da gestão escolar concorre para alcançar os fins instituídos em lei e por quais experiências pedagógicas em educação integral, além disso, quais seus desafios? A metodologia consistiu numa revisão histórica sobre as principais experiências pedagógicas com educação integral no Brasil: tempo integral, educação integral liberal e educação integral politécnica; aplicação de survey multifatorial às escolas da base empírica e análise dos resultados por meio do materialismo histórico. Chegou-se à conclusão: por mais que a gestão escolar tenha apresentado uma tendência a práticas democráticas, dois obstáculos precisam ser superados: o espontaneísmo afetivo e o gerencialismo burocrático. Além disso, aplicar os princípios da LDB pela perspectiva do movimento sindical e pôr em prática uma gestão democrática superadora da educação integral, sob a forma de tempo integral.

Palavras-chave: Gestão democrática. Educação integral. Educação de tempo integral. Educação integral liberal. Educação integral politécnica.

Mestre em Educação pela Fundação Universidade Federal de Rondônia; doutoranda em Educação pela Universidade Federal do Amazonas.

2 Doutora em Educação: História, Política, Sociedade pela Pontifícia Universidade Católica de São Paulo; Mestre em Educação pela Universidade Federal do Amazonas. 
Abstract: In the state of Amazonas, the integral education system consists of two subsystems: one, from the State Full-Time Schools - EETls, and another, from the State Full-Time Centers - CETIs. This article is the result of a research carried out in 2014 in three State Full-Time Schools - EETls, with the objective of verifying in which working conditions, the praxis of school management competes to achieve the purposes established by law and for what pedagogical experiences in integral education, besides, what are its challenges? The methodology consisted of a historical review of the main pedagogical experiences with integral education in Brazil: full time, liberal integral education and integral polytechnic education; application of a multifactorial survey to schools with an empirical basis and analysis of results through historical materialism. The conclusion was reached: however much school management has shown a tendency towards democratic practices, two obstacles must be overcome: affective spontaneism and bureaucratic managerialism. In addition, apply the principles of the LDB from the perspective of the Union Movement and put into practice a democratic management that surpasses integral education, in the form of integral time.

Keywords: Democratic management. Integral education. Integral time education. Liberal integral education. Polytechnic integral education.

Resumen: En el estado de Amazonas, el sistema de educación integral consta de dos subsistemas: uno de las Escuelas Estatales de Tiempo Completo - EETl y otro de los Centros Estatales de Tiempo Completo - CETI. Este artículo es el resultado de una investigación realizada en 2014 en tres Escuelas Estatales de Tiempo Completo - EETl, con el objetivo de verificar en qué condiciones de trabajo, la praxis de la gestión escolar compite para lograr los fines establecidos por la ley y para qué experiencias pedagógicas en la educación integral, además, ¿̇cuáles son tus retos? La metodología consistió en una revisión histórica de las principales experiencias pedagógicas con educación integral en Brasil: tiempo completo, educación liberal completa y educación politécnica completa; Aplicación de una encuesta multifactorial a las escuelas con base empirica y análisis de resultados a través del materialismo histórico. Se llegó a la conclusión: por mucho que la gestión escolar haya mostrado una tendencia hacia las prácticas democráticas, hay que superar dos obstáculos: el espontaneismo afectivo, el gerencialismo burocrático. Además, aplicar los principios de la LDB desde la perspectiva del movimiento sindical y poner en práctica una gestión democrática que supere la educación integral, en la modalidad de jornada completa.

Palabras clave: Gestión democrática. Educación integral. Educación a tiempo completo. Educación integral liberal. Educación integral politécnica. 


\section{INTRODUÇÃO}

Este artigo resulta de uma pesquisa realizada, em 2014, em três Escolas Estaduais de Tempo Integral - EETls, com o objetivo de analisar a gestão democrática, nesse subsistema, implantado em 2002, na cidade de Manaus, estado do Amazonas.

Tendo por base o conceito gestão democrática, expresso na Lei 9.394/1996, e as modalidades de educação integral consagradas no Brasil, tenta verificar, em que condições de trabalho, a práxis da gestão escolar concorre para alcançar os fins instituídos em lei e por experiências pedagógicas em educação integral e, além disso, quais seus desafios?

Nesse sentido, para alcançar os objetivos deste artigo, inicialmente, far-se-á uma comparação entre as duas modalidades de educação integral mais conhecidas. Em seguida, caracterizar-se-á o sistema de educação integral de Manaus para, finalmente, analisar os resultados da pesquisa e, a partir destes, indicar os caminhos alternativos para a educação integral, em Manaus.

\section{QUADRO TEÓRICO: EDUCAÇÃO INTEGRAL UERSUS EDUCAÇÃO DE TEMPO INTEGRAL}

Por indicativo do Plano Nacional de Educação de $2001^{3}$ e, principalmente, da Portaria Interministerial n. 17, de 24 de abril de 2007, que institui o Programa Mais Educação, os entes federativos têm se empenhado em desenvolver políticas, que visem a implantação da educação integral nas redes públicas de ensino. Essa política é regulamentada pelo Decreto n. 7.083/2010, de 27 de janeiro de 2010, e concretizada como política federal pela Lei n. 13.005/2014, de 25 de junho de 2014 .

No período de tempo supraindicado (2001-2014), reacendeu no Brasil, a discussão acerca da natureza da educação integral e de suas finalidades.

Para Cavaliere, a crise por que passa a escola pública brasileira tem levado os governos a buscarem medidas, que possam responder a essa crise. De acordo com essa autora:

Busca-se, de forma pouco explícita e pouco sistematizada, um novo formato para essa escola que associe a instrução escolar a uma forte ação no

Veja-se a propósito Lei n. 10.172/2001 (BRASIL, 2001, p. 6, 10, 11, १3, 18, 21). 
campo da socialização primária e da integração social de contingentes da população ainda em grande parte pouco marcados pelo ethos escolar. (CAVALIERE, 2002, p. 250).

Esse novo formato para a escola pública consiste na política de educação integral instituída a partir de 2007 que, conforme evidências legais, visa ao atendimento de demandas sociais, cuja história de vida está pouco vinculada à cultura escolar.

Tais evidências se encontram no parágrafo único do Art. $1^{\circ}$ da Portaria n. 17/2007 “0 programa será implementado por meio do apoio à realização, em escolas e outros espaços socioculturais, de ações socioeducativas [...] garantia da proteção social da assistência social [..." (BRASIL, 2007, p. 2); no parágrafo segundo do Art. $1^{\circ}$ do Decreto n. 7.083/2010, no qual "A jornada escolar diária será ampliada com o desenvolvimento das atividades de acompanhamento pedagógico [...] práticas de prevenção aos agravos à saúde, promoção da saúde e da alimentação saudável [...]" (BRASIL, 2010, p. 1); na Lei 13.005/2014, que ratifica "Instituir, em regime de colaboração, programa de construção de escolas [...] para atendimento em tempo integral, prioritariamente em comunidades pobres ou com crianças em situação de vulnerabilidade social." (BRASIL, 2014, p. १2). ${ }^{4}$

Assim, a educação de tempo integral tem duas características básicas: a proteção social aos mais pobres e a ampliação do tempo escolar.

A ampliação do tempo e das funções sociais, no entanto, não é recente. Essa concepção de educação integral remonta aos anos 1920 e se desenvolve nos anos 1930, entre duas correntes de pensamento contrárias. De acordo com Cavaliere (2010, p. 249):

\footnotetext{
No Brasil, a compreensão da maneira pela qual a concepção de educação integral se desenvolve passa obrigatoriamente pelo estudo do pensamento educacional das décadas de 20 e 30 do século XX. A educação integral, significando uma educação escolar ampliada em suas tarefas sociais e culturais, esteve presente nas propostas das diferentes correntes políticas que se delinearam naquele período. As correntes autoritárias e elitistas a encampavam com o sentido de ampliação do controle social e dos processos de distribuição criteriosa dos individuos nos segmentos hierarquizados da sociedade. 0 extremo dessa tendência expressou-se na concepção de educação integral da Ação Integralista Brasileira. Já as correntes liberais encampavam a educação integral como objetivo de reconstrução das bases sociais para $\circ$ desenvolvimento democrático, o qual só poderia se dar a partir de individuos intencionalmente formados para a cooperação e a participação. Entre os liberais, destaca-se o nome de Anísio Teixeira, por sua significativa elaboração teórica e técnica, visando à ampliação das funções da escola e o seu fortalecimento como instituição.
} 
As duas concepções liberais de educação integral, a conservadora, da Ação Integralista Brasileira, e a democrática, de Anísio Teixeira, permanecem ainda hoje, mas Anísio Teixeira não só sistematizou, mas também concretizou sua proposta educacional, tanto por meio do Centro Educacional Carneiro Ribeiro, inaugurado em Salvador, em 1950, quanto da Escola-Parque 308 - Sul, inaugurada em Braślia, em 1960.

No discurso inaugural da primeira, Teixeira (1959, p. 79) expressa sua concepção educacional assim:

\begin{abstract}
E desejamos dar-the seu programa completo de leitura, aritmética e escrita, e mais ciências físicas e sociais, e mais artes industriais, desenho, música, dança e educação física. Além disso, desejamos que a escola eduque, forme hábitos, forme atitudes, cultive aspiraç̃̃es, prepare, realmente, a criança para a sua civilização - esta civilização tão difícil por ser uma civilização técnica e industrial e ainda mais difícil e complexa por estar em mutação permanente. E, além disso, desejamos que a escola dê saúde e alimento à criança, visto não ser possivel educá-la no grau de desnutrição e abandono em que vive.
\end{abstract}

Vê-se que a concepção abrange o ensino das ciências, da formação para o trabalho, das artes, do corpo, criação de hábitos culturais direcionados à vida na sociedade industrial e democrática, além das bases necessárias para isso, como saúde e alimentação. Portanto, para além da proteção social aos mais pobres e da ampliação do tempo, a educação liberal democrática de Anísio Teixeira, visa a uma formação escolar para a vida em sociedade e para o mundo do trabalho, ainda que, a princípio, trabalho subalterno. A concretização de tal concepção se completou com a Escola-Parque de Brasília, DF.

Com as condiç̃es que the foram postas, pelo governo de Juscelino Kubitschek (1956-1961), incluindo capacidades tais como Oscar Niemayer, Darcy Ribeiro e Burle Marx, pode, então, completar a sua obra pedagógica com uma estrutura arquitetônica, que correspondesse plenamente à suas ideias. Sua concepção educacional não cabia numa escola pura e simples. Diz ele: "Dai falar-se antes em Centro do que em Escola. 0 Centro de Educação Elementar compreende pavilhões de 'jardim de infância', de 'escola-classe', de 'artes industriais', de 'educação fisica', de 'atividades sociais', de 'biblioteca escolar' e de 'serviços gerais'." (TEIXEIRA, 1961, p. 195).

A integração dos currículos com os espaços escolares é uma aspiração que busca desde suas experiências, quando Diretor de Ensino da Capital Federal, cuja marca se concretiza com a construção da Escola-Parque de Brasilia. 
Desde então, educação integral no Brasil é entendida como processo educativo, que visa ao desenvolvimento das múltiplas faculdades humanas, para as quais setores escolares específicos deveriam ser construídos. ${ }^{5}$

Mediante a esta compreensão se entende, desde logo, que educação integral se distingue de educação de tempo integral: aquela visa a uma preparação integral do ser humano, esta a uma preparação parcial, ainda que o horário escolar se estenda por todo o dia.

Mas há algo que as une. As propostas de tempo integral decorrentes das normas legais de 2007 a 2014, além de experiências pedagógicas não analisadas aqui, ${ }^{6}$ tanto quanto a proposta liberal-democrática de Teixeira, visam a uma formação humana que se conforma ao trabalho subalterno, necessário à sociedade liberal-capitalista, portanto, por princípio, meio e fim, antagônica a qualquer concepção emancipatória do trabalho. ${ }^{7}$

Ora, o trabalho é determinado por quem o realiza, mas esse ato, inversamente, produz a sua própria condição humana. A identidade entre trabalho e ser humano condicionam a humanidade de sua natureza. Assim, se o ato de produzir as condições necessárias à sua existência o torna humano, a forma como realiza o trabalho, o torna histórico, um ser em constante transformação. Ao interpretar uma passagem essencial da concepção marxiana, Saviani (2007, p. 154) sintetiza a concepção e a definição de trabalho que se utiliza aqui:

[...] ○ ato de agir sobre a natureza transformando-a em função das necessidades humanas é o que conhecemos com o nome de trabalho. Podemos, pois, dizer que a essência do homem é o trabalho. A essência humana não é, então, dada ao homem; não é uma dádiva divina ou natural; não é algo que precede a existência do homem. Ao contrário, a essência humana é produzida pelos próprios homens. 0 que o homem é, é-o pelo trabalho. A essência do homem é um feito humano. É um trabalho que se desenvolve, se aprofunda e se complexifica ao longo do tempo: é um processo histórico.

A importância do trabalho no processo de formação do ser humano remete, então, à importância do trabalho no processo de formação educacional e, por conseguinte, à criação do conceito "trabalho como princípio educativo".

A produção desse conceito e de sua efetivação como princípio da prática escolar remonta à interpretação, que Manacorda e Gramsci dão à concepção de educação de Marx.

5 São exemplos da integração entre concepção educacional e projeto arquitetônico escolar, além das escolas de Anísio Teixeira, os CIEPs (RIBEIRO, 1986), os CEUs (PACHECO, 2009; SANCHES, 2014), a proposta do Projeto Burareiro de Educação Integral (MACIEL, 2016, p. 19-40; MOREIRA; JUNQUEIRA; MACIEL, 2013, p. 113-130) e a proposta constante da estratégia “6.2”, da meta "6" do PNE/2014 (BRASIL, 2014).

6 A exemplo das propostas significativas dos CIEPs e dos CEUs, referenciadas acima.

7 A concepção emancipatória do trabalho de que se fala, pode ser encontrada em Saviani (2007, p. 154-155, 2003, p. 132-135). 
Nessa intepretação se baseiam a maioria absoluta das interpretações brasileiras, ligadas, ou não, ao grupo trabalho e educação, da ANPED.

Mas a ênfase que a interpretação dos autores brasileiros dá à união entre trabalho e educação, não raramente excluindo a dimensão física, e restringindo sua aplicação ao Ensino Médio, tem sofrido inúmeras críticas, entre as quais a de Maciel (2018, p. 90-91), para quem esses autores:

[...] ou trataram "o trabalho como princípio educativo" como fundante da natureza humana e, portanto, como princípio geral da condição humanizante do trabalho (SAVIANI, 2003, p. 132-133; FRIG0TTO, CIAVATA e RAMOS, 2013, p. 02), ou reduziram a concepção de "trabalho como princípio educativo" a um processo de união entre educação e trabalho a ser operado no ensino médio e nos cursos profissionais e técnicos (SAVIANI, 1989, p. 12, 2003, p. 136 e 2007, 160; KUENZER, 1989, p. 23; MACHADO, 1991, p. 60; FRIG0TTO, CIAVATA e RAMOS, 2012, p. 41-46; 2013, p. 7-8).

Sem desconsiderar a importância do conceito "trabalho como princípio educativo", mas, ao mesmo tempo, demonstrando suas limitações, Maciel $(2018)^{8}$ assegura que o "trabalho como princípio educativo" carece de um princípio pedagógico, que the possibilite operacionalizar os processos educativos na escola, então propõe a "politecnia como princípio pedagógico". 0 princípio pedagógico da politecnia para Maciel e Braga (2007, p. 61) é constituído por quatro dimensões:

A cognoscibilidade, como desenvolvimento das dimensões lógico-cognitivas e psíquicas (onde o conhecimento científico e tecnológico seja determinante); a habilidade, enquanto expressão de capacidades psicomotoras e físicas londe o esporte e a formação profissionalizante constituam suportes fundamentais); a sensibilidade, como potencialização de todos os sentidos (onde a música, a dança, a literatura, o teatro e as artes visuais, gráficas e plásticas tenham lugar privilegiado); e a sociabilidade, enquanto efetivo exercício político da práxis social (onde a cidadania participativotransformadora, a ecologia humana crítica e a saúde tenham prioridade).

0 trabalho educativo-pedagógico, dessas quatro dimensões, pela escola, daria conta de proporcionar, ao educando, as condições de seu desenvolvimento integral: trabalho não seria apenas a formação para o trabalho, mas a base integradora, e por isso mesmo

8 Na seção "Dos limites do trabalho como princípio educativo" Maciel (2018, 88-94) analisa alguns dos principais autores brasileiros para demonstrar a tese da insuficiência pedagógica do conceito "trabalho como princípio educativo". 
politécnica, de todos os processos educativos que, em si, já são trabalho. A esse mundo educativo o autor chama de educação integral politécnica. ${ }^{9}$

Com isso, pode-se assegurar que, as dezenas de experiências pedagógicas brasileiras sob a tutela de concepções de educação integral, podem ser sintetizadas em três modalidades: a educação integral de tempo integral, a educação integral liberal e a educação integral politécnica.

Em qual modalidade a educação integral da cidade de Manaus se enquadra, como se constituiu historicamente, quais seus desafios? Eis o que se tentará responder neste artigo.

\section{BASE EMPÍRICA: CONTEXTO HISTÓRICO E ESTRUTURA}

Antes mesmo da institucionalização da política de educação integral do governo federal, em 2007, o estado do Amazonas começou a implantar a sua política de educação integral.

Essa seção se destina a uma breve caracterização do contexto dessa implantação e à descrição das escolas onde ocorreu a coleta de dados, a base empírica desta pesquisa.

\subsection{CONTEXTO HISTÓRICO DA IMPLANTAÇÃO DA EDUCAÇÃO INTEGRAL EM MANAUS}

A escola pública brasileira vive uma profunda crise de qualidade, desde que se propôs à universalização do acesso, em $19711^{10}$ Nos últimos quinze anos, visando encontrar alternativas a essa crise, o governo brasileiro vem indicando o caminho da educação em tempo integral, através de políticas que se tornaram mais efetivas, a partir de 2007 . No Amazonas, particularmente em Manaus, essa política parece ter começado em 2002, mas há controvérsia.

9 A proposta da educação integral politécnica está delineada em “Projeto Burareiro de Educação Integral: original” (MACIEL, 2016) e analisada em "Fundamentos da educação integral politécnica: da teoria à prática" (MACIEL; JACOMELL; BRASILEIRO, 2017).

10 Ratifica-se: a trajetória da universalização do ensino público começa com a Lei 5.697/71 e não na década dos anos 1990. Nesta já alcança, praticamente, por dados do ano de 1995, a universalização do Ensino Fundamental, de acordo com MEC/ INEP (1997, p. 6), confirmada por Oliveira (2007, p. 673) e Assis (2012, p. 322, 332, 336). 
De acordo com Ferreira (2012), a origem da política de educação integral, em Manaus, remonta à necessidade de substituir o Projeto dos Centros de Excelência Profissional, extinto com o advento da Lei 9.394/96 e do Decreto Federal 2.208/97. A política de tempo integral nasce com o Projeto Experimental de Tempo Integral", que passa a funcionar, em 2002, nas Escolas Petrônio Portela e Marcantonio Vilaça I, durante o Governo Amazonino Mendes (1999-2002).

Se, de fato, o Projeto começa em 2002 é uma incógnita: A Resolução № 112 (AMAZONAS, 2008), do Conselho Estadual de Educação do Amazonas, que aprova o "Projeto das Escolas de Tempo Integral", é de 20 de outubro de 2008 e não faz nenhuma referência ao ano de início do Projeto.

0 que é irrefutável é que a política educacional de tempo integral, em Manaus, se materializa com a criação das Escolas Estaduais de Tempo Integral - EETls, em 2008, e com a criação dos Centros Educacionais de Tempo Integral - CETls, a partir de 2010,12 durante o governo Eduardo Braga (2007-2010), coincidente com as edições das políticas federais de educação integral, tanto da Portaria de 2007, quanto do Decreto de 2010.

Até o ano de 2010, as Escolas de Tempo Integral da rede Estadual de Ensino que ministravam o ensino do $1^{\circ}$ ao $5^{\circ}$ ano do Ensino Fundamental eram: E. E. Roxana Pereira Bonessi, E.E. Santa Terezinha, E. E. Nossa Senhora das Graças, E. E. Almirante Barroso, E. E. Machado de Assis, E.E. Helena Araújo, CETI Garcitylzo Lago e Silva e CETI Rafael Henrique Pinheiro dos Santos e atendiam, conforme Ferreira (2012) a 2.574 (dois mil, quinhentos e setenta e quatro) alunos.

As escolas que ministravam do $6^{\circ}$ ao $9^{\circ}$ do Ensino Fundamental eram: E.E. Djalma Batista, E.E. Marquês de Santa Cruz, E. e. Prof ' Leonor Santiago Mourão, E. E. Altair Severiano Nunes, CETI Garcitylzo Lago e Silva, E. E. Isaac Benzecry, E. E. Irmã Gabrielle, CETI Marcantonio Vilaça II, CETI Zilda Arns, CETI João dos Santos Braga, CETI Elisa Bessa e CETI Prof ${ }^{a}$ Cinthia Régia e respondiam por 6.600 (seis mil e seiscentos) alunos.

As escolas de tempo integral que ministravam do $1^{\circ}$ ao $3^{\circ}$ ano do Ensino Médio eram: E.E. Senador Petrônio Portela, E. E. Marcantonio Vilaça, Instituto de Educação do Amazonas - IEA, CETI Marcantonio Vilaça II, CETI Zilda Arns, E.E. Zilda Arns, E. E. Irmã Gabriele, CETI João dos Santos Braga e atendiam a 2.538 (dois mil quinhentos e trinta e oito) alunos.

" Sobre este Projeto, porém, até o presente momento, nenhuma das pessoas contatadas, da SEDUC e da Escola, soube dar informações precisas.

12 0 sistema estadual de educação integral de Manaus está constituído por dois subsistemas: o constituido por escolas especialmente construídas para atender em tempo integral - os CETls, e o constituído por escolas adaptadas - as EETls. 
Como o primeiro CETI - Centro Educacional de Tempo Integral foi inaugurado apenas em 2010, a coleta de dados recaiu sobre as EETls - Escolas Estaduais de Tempo Integral.

\subsection{METODOLOGIA: BASE EMPÍRICA E TÉCNICA DE COLETA DE DADOS $^{13}$}

Antes, porém, de apresentar a coleta de dados sobre a constituição do sistema de educação integral de Manaus, pensa-se apropriado expor uma nota metodológica para evitar generalizações.

A natureza histórica do fenômeno educacional, bem como a diversidade de situações particulares, determinadas por fatores sociais, econômicos, políticos, culturais, mesmo numa área geográfica, aparentemente, homogênea pela extensão limitada, deve, sempre, levar o pesquisador a acautelar-se sobre inferências e generalizações.

Nesse sentido, três limitações desse estudo, devem ser explicitadas: a primeira que diz respeito à complexidade do tema, dada a diversidade de concepções de educação integral, que repercutem direta e imediatamente nas formas de gestão, na organização curricular e nas propostas metodológicas; e, a segunda, ao tempo limitado da pesquisa de campo, cujo survey multifatorial, para maior fidedignidade, prevê um período um pouco mais prolongado de observação sistematizada, o que não ocorreu. A coleta de dados foi realizada em três semanas, cinco dias em cada escola, no mês de outubro de 2014; e a tabulação entre 14 novembro de 2014 e 16 de fevereiro de 2015.

Na discussão dos critérios para a seleção das escolas, levou-se em conta: a localização, tendo em vista que das seis regiões da cidade, quatro são bem diferenciadas socialmente; o tipo de escola: EETls ou CETls, ou os dois; a modalidade da Educação Básica: Ensino Fundamental I, II ou Ensino Médio, ou ambas. Decidiu-se, por custos financeiros e operacionais, pelas EETls de uma mesma região, a Zona Sul de Manaus, o que é outra limitação.

0 survey multifatorial foi constituído por dois instrumentos: um formulário geral com 48 (quarenta e oito) itens, preenchido pelos pesquisadores através de observação e entrevista com gestores e professores; e outro, com 23 (vinte e três) questões fechadas e de múltipla escolha, preenchido por administrativos, docentes e gestores (MACIEL; SILVA; MOURÃ0, 2014a).

13 banco de dados resulta da pesquisa de campo para elaboração da dissertação de mestrado de Silva (2017). 
A coleta de dados foi realizada em três momentos: no primeiro, aplicou-se o questionário com a finalidade de testá-lo; no segundo, procedeu-se à observação sistemática da estrutura e do funcionamento da escola, e entrevistaram-se dirigentes e coordenadores; no terceiro, aplicou-se o questionário e entrevistaram-se professores e gestores.

0 survey multifatorial foi testado na Escola Estadual de Tempo Integral - EETI "Santa Tarcila" (nome fictício) e aplicado a três outras escolas, aqui denominadas, por razões éticas de: a) EETI-1; b) EETI-2; c) EETI-3, que constituem a base empírica da pesquisa. A primeira dessas escolas atende ao Ensino Fundamental II ( $6^{\circ}$ ao $9^{\circ}$ ano) e as duas outras, ao Ensino Fundamental I ( $1^{\circ}$ ao $5^{\circ}$ ano), conforme apontam os dados tabulados pela ferramenta Excel (MACIEL; SILVA; MOURÃO, 2015a, 2015b, 2015c). Os resultados do cruzamento dos dados, das respectivas escolas, foram tabulados pela ferramenta Excel (MACIEL; SILVA; MOURÃ0, 2015d).

\subsection{ESTRUTURA DAS ESCOLAS DA BASE EMPÍRICA}

As Escolas Estaduais de Tempo Integral são escolas adaptadas para atender ao regime escolar de tempo integral. As selecionadas para a coleta de dados estão localizadas na Zona Sul de Manaus.

A EETI-1 foi criada em 1980. Situada no Bairro Japiim, iniciou suas atividades, em março de 1980, atendendo ao antigo Ensino de $1^{\circ}$ Grau, nos turnos matutino e vespertino e, no noturno, o Ensino de $2^{\circ}$ Grau, com cursos profissionalizantes em Educação para o Lar, Técnicas Comerciais, Técnicas Agrícolas e Técnicas Industriais.

A partir de 1987, a Escola passou a oferecer, além dos cursos já citados, o Curso Profissionalizante de Técnico em Clínica. Durante os anos de 1998 a 2000, a Escola foi transformada em Centro de Excelência Profissional em Saúde. Em 2006 a Escola passa a funcionar em regime de tempo integral do $6^{\circ}$ ao $9^{\circ}$ ano do Ensino Fundamental.

De julho de 2010 a dezembro de 2015, a escola encerrou suas atividades no prédio do Bairro Japiim para ser reformada, e passou a funcionar no recém-inaugurado CETI Prof. Gilberto Mestrinho, na Av. Leopoldo Peres, no Bairro Educandos, voltando ao Japiim em janeiro de 2016, motivo pelo qual decidiu-se não fazer a descrição física da escola.

A escola atendia, no ano da coleta de dados, nos turnos pesquisados, do $6^{\circ}$ ao $9^{\circ}$ ano, e contava com 02 diretores; 47 professores; 1084 alunos (675, no diurno integral); 01 coordenador pedagógico; 05 funcionários administrativos (03, no diurno); 05 funcionários de apoio e 01 instrutor de atividades sociocultural-esportivas. A segurança e limpeza da escola são realizadas por funcionário de empresa terceirizada. 
A EETI-2, situada no bairro Educandos, atende do $6^{\circ}$ ao $9^{\circ}$ ano, e conta com 01 diretora, 31 professores, 305 alunos, 01 coordenador pedagógico, 02 funcionários administrativos, 02 funcionários de apoio e 02 instrutores de atividades sociocultural-esportivas. A segurança e limpeza da escola são realizadas por funcionário de empresa terceirizada. Vale salientar que, entre as escolas pesquisadas, é a única escola que possui um sistema de tratamento de esgoto.

A infraestrutura dispõe de: 15 salas de aula climatizadas, 05 salas de projetos especiais, 01 diretoria, 01 sala de professores, 01 secretaria, 01 sala para coordenação pedagógica, 01 biblioteca, 01 cozinha, 01 almoxarifado, 01 laboratório de informática, 01 refeitório, 04 banheiros masculinos e 04 banheiros femininos, pátio interno. Constatou-se a inexistência de acessibilidade para portadores de deficiência.

A EETI-3, situada no bairro Colônia de Oliveira Machado foi inaugurada em 2004. Em 2007, a EETI-3 foi a primeira escola do estado do Amazonas a oferecer educação em tempo integral, do $1^{\circ}$ ao $5^{\circ}$ ano do Ensino Fundamental.

A justificativa para que essa escola tenha sido a primeira a oferecer Tempo Integral, segundo a diretora decorreu das características do bairro: sendo um dos portos principais de Manaus, muitos habitantes são feirantes, carregadores de peixe, vigilantes, estivadores, vendedores ambulantes, carreteiros, etc., com alta incidência de prostituição, consumo e tráfico de drogas, assassinatos, e favelas nos morros e palafitas nas baixadas.

A infraestrutura física dispõe de: 11 salas de aula climatizadas, 01 sala de mídias, 01 diretoria, 01 sala de professores, 01 secretaria, 01 sala para coordenação pedagógica, 01 biblioteca, 01 laboratório de informática, 01 laboratório de ciências, 01 brinquedoteca, 01 cozinha, 01, depósito, 01 refeitório, 05 banheiros masculinos e 05 banheiros femininos, pátio interno e elevador para pessoas portadoras de deficiência.

0s recursos humanos são constituídos por: 01 diretora, 22 professores, 439 alunos, 01 coordenador pedagógico, 02 funcionários administrativos, 02 funcionários de apoio e 02 instrutores de atividades sociocultural-esportivas. A segurança e limpeza da escola são realizadas por funcionários de empresa terceirizada.

0 marco na história dessa escola foi alcançar, no ano de 2010, o Certificado de Qualidade ISSO: 9001:2008, e em processo para obtenção do Certificado ISSO 14000. Desde então, Escola passou a integrar o seleto time das quatro escolas do estado do Amazonas associadas à Rede do PEA-UNESCO. 


\section{ANÁLISE DOS RESULTADOS}

Tabulados os dados coletados, procedeu-se, primeiramente, a uma análise dos resultados de cada escola para, em seguida, analisá-los em conjunto. No caso específico deste artigo, é essa análise de conjunto, focada na gestão dos recursos humanos e técnicopedagógicos, que será exposta.

\subsection{CONCEPÇÕES CONSTITUÍDAS DE GESTÃO ESCOLAR}

A gestão escolar tem origem na administração escolar, e esta, na administração de empresa. Legal e formalmente, de 1971 (Lei 5.692/71) até a Constituição de 1988, a gestão escolar era orientada por teorias, oriundas da administração de empresa. Na prática, a nova concepção de gestão escolar, decorrente da Constituição de 1988, e só começa a ser substituída (dependendo da força local do movimento sindical de docentes), a partir de 1996, ano de promulgação da Lei 9.394/96.

É a Constituição de 1988 que traz, coerente com a natureza da democracia liberal que se instalava, a novidade de princípios, que devem reger a administração pública: a legalidade, a impessoalidade, a moralidade, a publicidade e a eficiência.

Na interpretação de Cury (2002, p. 167-168), com a qual se concorda: a legalidade - obediência à ordem jurídica e democrática; a impessoalidade - imposição, ao poder público, do governo das leis ao governo dos homens, evitando favorecimento particular gerador do tratamento desigual; a moralidade - respeito os princípios anteriores, às regras e normas de conduta estabelecidas; a publicidade - transparência dos atos do poder público pelo que se possibilita o controle dos atos governamentais; eficiência - celeridade e padrão de qualidade na prestação dos serviços públicos. De acordo com Cury (2002, p. 168):

\footnotetext{
Estes princípios, se e quando efetivados, colocam a transparência, o diálogo, a justiça e a competência como transversais à cidadania democrática e republicana. Eles, se válidos para todo e qualquer servidor público, com maior razão, se aplicam aos que detém uma parcela de autoridade no âmbito do serviço público.
}

0 entendimento dessa concepção de democracia, com o apoio histórico do movimento sindical docente (uma vez que era uma de suas bandeiras de luta) repercutirá diretamente na Lei 9.394/96. 
Com efeito, o inciso VIII do Art. $3^{\circ}$ torna a gestão democrática um princípio do exercício profissional na Educação Básica e o Art. 14 estabelece autonomia para que os sistemas de ensino definam as normas da gestão democrática, sob critérios de participação dos profissionais da educação e da comunidade local; enquanto que o Art. 64, ao situar, no mesmo nível, os profissionais de educação para administração, planejamento, inspeção, supervisão e orientação educacional, amplia não só os atributos para uma nova definição do conceito de gestão democrática, mas também atribui a esta a noção de trabalho coletivo.

Essa é a concepção legal de gestão democrática, mas não a única. Com o passar dos anos, coerente com o movimento de reestruturação produtiva e implantação do neoliberalismo, a ela será acoplada a concepção gerencialista dos Organismos Multilaterais, por meio dos Planos e Resoluções, que subsidiam o exercício da Gestão Escolar.

A gestão escolar gerencialista busca, de um lado, eficiência na execução dos serviços escolares, por meio da redução dos gastos públicos, descentralização administrativa e, de outro nos resultados do rendimento escolar, decorrentes de processos avaliativos (SILVA; ALVES, 2012; SILVA; SILVA; SANTOS, 2016, p. 536-539). Importa afirmar que a concepção gerencialista se embasa nos princípios generalistas, sutilmente consagrados na LDB de 1996 e, nesse sentido, não se trata de uma concepção contrária àquela (como, inclusive, os autores acima citados acreditam), mas seu aprofundamento na direção da concepção produtivista da escola, em meio ao universo da gestão democrático-participativa, ${ }^{14}$ na qual a comunidade escolar se vê intensificada de tarefas e projetos com as mínimas condições de trabalho.

Interessantemente, a concepção de gestão democrática defendida pelo setor hegemônico do Movimento Sindical Docente se baseia na efetivação dos princípios democráticos de gestão consolidados pela LDB de 1996, contrapondo estes à gestão gerencialista. A diferença básica, no essencial, reside em reivindicações para que se efetivem postulados instituídos, relativos à carreira, ao salário e à formação docente. Assim, desde que as relações de trabalho sejam democrático-participativas; hajam condições salubres de trabalho; carreira, salário e formação supostamente condizentes com a dignidade social da profissão, aceita-se a ordem liberal. ${ }^{15}$

Questões fundamentais para a gestão como a organização e finalidades do trabalho educativo, do tipo de escola e de educação não fazem parte da pauta do movimento

14 De que são pródigos os manuais e orientações do MEC, via Secretaria de Educação Básica ou cursos promovidos por esta, para estados e municípios, mesmo no período em que muitos acreditavam na plena democracia. Ver, bem a propósito Brasil (2004a, 2004b) e Gracindo (2007).

150 conjunto dessas concepções podem ser facilmente constatadas no site da CNTE - Confederação Nacional dos Trabalhadores em Educação (2019), pauta principal, embora seja o FUNDEB, recai sobre salários, a concepção democrática pode ser deduzida da própria formação dos quadros sindicais (PARÊS, 2014), a proposta oficial para a Educação Básica se encontra em BRASIL (2016). 
sindical docente, a não ser como como aportes secundários, inseridos como apêndices da ordem liberal ou, quando muito, socialdemocrata. ${ }^{16}$

\subsection{A GESTÃO DOS RECURSOS HUMANOS}

Qualquer que seja o tipo de gestão, esta administra quatro grupos de recursos: humanos, materiais, financeiros e técnico-pedagógicos.

Os recursos humanos são constituídos por diretores, coordenadores pedagógicos (no mais das vezes, supervisores escolares, orientadores educacionais, psicólogos educacionais), professores, alunos e técnico administrativos. Outros atores como país de alunos e representantes da comunidade não são vinculados diretamente, embora, às vezes, tenham atuação destacada.

Os recursos materiais são constituídos pelos insumos necessários à manutenção da escola e à execução dos processos educativo-pedagógicos e que vão do almoxarifado à despensa de alimentos, dos materiais pedagógicos aos recursos tecnológicos, etc.

Os recursos financeiros são constituídos pelas verbas que são recebidas da secretaria de educação, do governo federal, dos projetos especiais financiados por empresas privadas, etc.

Os recursos técnico-pedagógicos, além do material didático, são constituídos pela capacidade técnico-científica disponível para mobilizar a formação pedagógica de discentes e docentes, principalmente, sem desconsiderar os outros atores da comunidade escolar.

Nesse artigo, a análise recairá sobre a gestão dos recursos humanos e os técnico-pedagógicos. Os dados aqui analisados se referem à média dos escores das três escolas.

Por esses dados, conforme se observa na Tabela 1, é possivel perceber que 83\% do corpo escolar (incluindo diretores, coordenadores pedagógicos, professores) é do sexo feminino e $17 \%$ do masculino, dentre os quais $70 \%$ se consideram pardos contra $24 \%$ brancos e $6 \%$ pretos; distribuídos por 50\% na faixa-etária entre 30 e 40 anos; $20 \%$ entre 20 e 30 anos; $13 \%$ entre 40 e 50 anos; e, $17 \%$ entre 50 e 60 anos.

16 Esse fato é agravado, quando se constata que há, hoje, no Brasil, 1 Centrais Sindicais, a maioria das quais pelegas, criadas para dividir o movimento sindical brasileiro. 
Tabela 1 - Taxa do efetivo docente função, gênero, faixa-etária e raça

\begin{tabular}{lrlrlrlr}
\hline \multicolumn{1}{c}{ Funções } & \multicolumn{1}{c}{$\%$} & Gênero & $\%$ & Faixa-etária & \multicolumn{1}{c}{$\%$} & Ético-racial & $\%$ \\
\hline Diretor & 6 & Feminino & 83 & Menos 20 & 0 & Branco & 24 \\
Coord. Pedagógico & 6 & Masculino & 17 & De 20 a 30 & 20 & Pardo & 70 \\
Professor & 80 & & & De 30 a 40 & 50 & Negro & 6 \\
Instrutor & 8 & & De 40 a 50 & 13 & Amarelo & 0 \\
& & & De 50 a 60 & 17 & Indigena & 0 \\
\hline
\end{tabular}

Fonte: Maciel, Silva e Mourão (2015d).

Assim, podemos afirmar que, em termos de gênero, há uma grande predominância do sexo feminino, resultado esse, certamente influenciado pelo fato de que duas, das três escolas pesquisadas, atendem aos anos iniciais do ensino fundamental.

Interessa notar, ainda, que $70 \%$ do corpo escolar tem até 40 anos de idade, o que é uma faixa-etária jovem, em termos força de trabalho ativa.

Com uma faixa-etária jovem e predominantemente feminina, de acordo com a diretora da EETI-3: "[...] assim, nosso trabalho se baseia na motivação dos nossos professores, são jovens e dispostos, têm amor pelo que fazem [...] trabalhamos em equipe para criar uma geração (de) que podemos nos orgulhar." Ainda de acordo com ela: "Quando há treinamento, ninguém se nega a participar." (informações verbais).

As afirmações, pela ótica por onde se vê, o materialismo histórico-dialético, expressam uma concepção espontaneísta de gestão, na qual subjaz uma das variantes do gerencialismo: o apelo afetivo, a motivação aproveitando o amor que os professores têm pelo ato de educar.

Os dados étnico-raciais constatados se aproximam dos dados oficiais, portanto, não há disparidades, apesar da histórica dificuldade de distinção entre cor e raça, quando se utiliza a autodeclaração: pardo decorre da miscigenação; indígena, quando há ascendência materna e paterna (IBGE, 2008). Pelos critérios do IBGE, a metade dos autodeclarados pretos pode ser de cor parda.

Tabela 2 - Taxa da formação acadêmica por nível escolar e por dependência administrativa

\begin{tabular}{lrlrlc}
\hline \multicolumn{1}{c}{ Escolaridade } & $\%$ & Instituição & $\%$ & Modalidade & $\%$ \\
\hline Ensino Fundamental & 0 & Federal & 40 & Presencial regular & 83 \\
Ensino Médio & 0 & Estadual & 30 & Presencial modular & 11 \\
Superior Completo & 37 & Municipal & 0 & À Distância & 6 \\
P-Graduação Lato Sensu & 59 & Privada & 30 & \\
P-Graduação Stricto Sensu & 4 & & &
\end{tabular}


A composição dos recursos humanos docentes (ver Tabela 2), incluindo diretoria, coordenação pedagógica, docência e instrutores socioculturais, apresenta-se satisfatória, em termos acadêmicos: $37 \%$ possui graduação completa; $59 \%$, pós-graduação lato sensu; e $4 \%$, stricto sensu. Do total, $40 \%$ possui graduação em universidade federal e $83 \%$, na modalidade presencial. Em termos funcionais, no entanto, levando em consideração as necessidades de recursos humanos específicos para a educação integral, os recursos humanos mostram a sua face calamitosa, pois se os professores representam $80 \%$ do total e os diretores $6 \%$; apenas $8 \%$ são instrutores de atividades socioculturais, do mesmo modo como somente $6 \%$ são coordenadores pedagógicos, conforme Tabela 1.

Portanto, mesmo considerando que as atividades esportivas são atribuições dos professores de educação física, a taxa de profissionais, tanto para as funções da coordenação pedagógica, quanto para as atividades socioculturais, é tão insignificante, que é impossivel imaginar, como essas as atividades podem ser desenvolvidas por tal quantitativo de profissionais.

Tabela 3 - Taxa da remuneração por faixa salarial e do trabalho por turno e por carga horária

\begin{tabular}{lrlrlr}
\hline \multicolumn{1}{c}{ Salário mínimo } & \multicolumn{1}{c}{ \% } & \multicolumn{1}{c}{ Turno de trabalho } & \multicolumn{1}{c}{ Carga horária } & $\%$ \\
\hline De 1 a 2 & 0 & Manhã & 0 & Até 20 horas & 0 \\
De 2 a 3 & 9 & Manhã e tarde & 98 & De 21 a 30 horas & 0 \\
De 3 a 4 & 51 & Tarde & 0 & De 31 a 40 horas & 81 \\
De 4 a 6 & 40 & Tarde e noite & 0 & Mais 40 horas & 17 \\
Acima de 6 & 0 & Manhã, tarde e noite & 2 & Não respondeu. & 2 \\
\hline
\end{tabular}

Fonte: Maciel, Silva e Mourão (2015d).

Observando-se a remuneração, por faixa salarial (Tabela 3) e ao se constatar que $60 \%$ ganha até quatro salários mínimos, dentre os quais $9 \%$ ganha de dois a três mínimos; e $40 \%$, de quatro a seis salários mínimos, compreende-se o porquê da prioridade formacional residir no âmbito das necessidades da progressão funcional. ${ }^{17}$

Não deixa de impressionar positivamente, todavia, a taxa de $98 \%$ de profissionais, que trabalham no diurno e a taxa de $87 \%$ dos que trabalham somente nas escolas pesquisadas. Se somarmos a isso, o dado de que $81 \%$ tem uma carga horária de 40 horas semanais, e $17 \%$, mais de 40 horas semanais, pode-se concluir que a concentração das

17 Os dados sobre salário, condições de trabalho, valorização profissional e jornada integral, em grande parte, confirmam os indicadores encontrados por Jacomini e Penna (2016). 
atividades do profissional numa só escola é um fator potencializador do rendimento produtivo, de um lado e, de outro minimizador da exaustão física do trabalhador, particularmente, quando se sabe que, boa parte dos professores, tem de se deslocar de uma escola para outra, na mudança de turno.

Os resultados expostos, acerca da formação e de algumas condições de trabalho, indicam que as escolas de educação integral pesquisadas em Manaus, que foram adaptadas, têm potencial para implementar uma gestão mais incisiva, em busca de uma modalidade de educação integral, voltada efetivamente para a formação integral e emancipatória dos discentes.

Essa afirmação se baseia no fato de que, nas entrevistas, não há menção a projetos especiais voltados para uma formação complementar, orientada para o mundo do trabalho e para a importância do Ensino Médio. No mais das vezes indicam a constatação de fragilidades, mas sem atitudes que possam revertê-las. A motivação não vai além da obtenção da simples aceitação para participar de cursos de formação, cujos fins residem no domínio técnico de uma metodologia de ensino em si mesma, sem apontar para um projeto educativo vinculado aos fins da educação integral de qualquer modalidade. Corroborando com as entrevistas, não se observou projetos, nesse sentido, em execução, a não ser aqueles que, de alguma forma, são financiados pelo terceiro setor ou buscam títulos oficiais.

\subsection{A GESTÃO DOS RECURSOS TÉCNICO-PEDAGÓGIICOS}

A expressão "recursos técnico-pedagógicos", já definida acima, consiste acima de tudo na capacidade técnico-científica disponível para mobilizar, principalmente, a formação pedagógica de docentes e indiretamente de discentes, para não falar dos outros atores da comunidade escolar.

Do ponto de vista estritamente educativo é o elo, que a capacidade gestora precisa encontrar, para juntar recursos humanos, a própria capacidade destes e os meios para desenvolvê-los. É o centro do trabalho educativo da gestão e da própria escola, ou pelo menos deveria ser.

Na “Proposta Pedagógica das Escolas da Rede Estadual de Ensino de Educação em Tempo Integral" da Secretaria de Estado da Educação, aprovada pelo Conselho Estadual de Educação do estado do Amazonas (AMAZONAS, 2008, p. 9), está exposto: 
Nas Escolas de Tempo Integral será desenvolvido o currículo básico, compreendendo os componentes curriculares da Base Comum Nacional e da Parte Diversificada, além das atividades escolares que ampliarão, por meio de projetos e oficinas, as possibilidades de aprendizagem dos alunos, com o enriquecimento do currículo básico, a partir da exploração de temas transversais e com a vivência de situações que favoreçam o aprimoramento pessoal, social, esportivo e cultural do estudante.

Cotejando esse parágrafo da "Proposta Pedagógica" da SEDUC, anexo da Resolução 112/2008 do CEE/AM, ${ }^{18}$ com os dois primeiros Artigos da Portaria Interministerial 17/2007 do MEC, observa-se coerência entre as duas, mas tanto numa, quanto na outra, a ideia de formação integral (Art. $1^{\circ}$, Port. 17/2007) não é nem desenvolvida, nem definida; no caso da "Proposta Pedagógica", nem mencionada. Antes pelo contrário, ao afirmar que, nas Escolas de Tempo Integral serão desenvolvidos os componentes da Base Comum Nacional e da Parte Diversificada, além das atividades que ampliarão as possibilidades de aprendizagem, deixa expresso, que essas atividades são apêndices daquela e não parte efetiva do currículo. A prova irrefutável desta afirmação é o quantitativo de recursos humanos contratados para a coordenação pedagógica e para o trabalho sociocultural da escola.

Veja-se o que informa a frieza dos números.

De acordo com a entrevista, o trabalho da coordenação pedagógica está centrado na orientação metodológica junto aos professores (84\%, EETI-1; 75\%, EETI-2; 100\%, EETI-3), mas como isso é possível dado o contingente de professores (47, EETI-1; 31, EETI-2; 22, EETI-3)? Além disso, é preciso considerar que há inúmeras outras atividades da coordenação, além da complexidade da metodologia utilizada pelas EETls. Diz uma das gestoras: "A metodologia utilizada pelos professores na escola é buscada na teoria sociointeracionista onde o indivíduo aprende interagindo com o meio em que se está inserido. Onde o professor e aluno se integram na construção do conhecimento." (informação verbal).

A palavra da diretora é parcialmente confirmada, pelos dados que apontam que $33 \%$ dos professores afirmou que utiliza a metodologia sociointeracionista, que é indicada pela escola; $11 \%$ indicaram outras metodologias e $56 \%$ não respondeu. Este grande percentual que não respondeu ou que indicou outras metodologias corrobora com outros dados coletados junto aos professores.

18 No documento da SEDUC o título é: "Proposta Pedagógica das Escolas da Rede Estadual de Ensino de Educação em Tempo Integral"; na Resolução, o título está modificado: Projeto das Escolas de Tempo Integral". 
Tabela 4 - Taxa de autonomia para a utilização de metodologia de ensino pelo professor

\begin{tabular}{|c|c|c|c|c|c|c|c|}
\hline $\begin{array}{l}\text { Escola indica } \\
\text { metodologia }\end{array}$ & $\%$ & $\begin{array}{c}\text { Metodologia adotada } \\
\text { pelo professor }\end{array}$ & $\%$ & $\begin{array}{c}\text { Escola permite professor } \\
\text { adotar metodologia }\end{array}$ & $\%$ & $\begin{array}{l}\text { Professor domina } \\
\text { uma metodologia }\end{array}$ & $\%$ \\
\hline Sim & 89 & Indicada pela escola & 33 & Sim & 87 & Sim & 91 \\
\hline Não & 7 & Outras & 1 & Não & 9 & Não & 7 \\
\hline Não & 4 & Não & 56 & Não & 4 & Não & 2 \\
\hline Respondeu & & Respondeu & & Respondeu & & Respondeu & \\
\hline
\end{tabular}

Fonte: Maciel, Silva e Mourão (2015d).

Perguntados se a escola tem uma metodologia orientada pela coordenação pedagógica: $89 \%$ respondeu que sim; $7 \%$, que não; e $4 \%$ não respondeu. Porém, de acordo com eles, a escola permite que o professor utilize uma metodologia de seu domínio (87\%), enquanto que $91 \%$ afirma que tem domínio sobre a metodologia utilizada. A elevada taxa de $91 \%$ para os que têm domínio sobre a metodologia utilizada contrasta com os $56 \%$, que não respondeu sobre qual metodologia utiliza, haja vista que, supostamente, uma pessoa que domina uma metodologia, deveria identificá-la.

Já que não foi perguntado ao professor se ele utiliza a metodologia da escola ou a de seu domínio, pelo menos dá para concluir que o processo didático-metodológico é democrático, uma vez que a escola pública, exatamente por esta natureza, não deve impor um referencial teórico-metodológico a seus professores.

Novamente aqui, os meios não estão voltados para fins expressos na política educacional. A forma como o trabalho é gerido e executado parece finalizar-se em si mesma, sem conexão com os fins mais abrangentes da educação, sem os fins mais específicos de uma teoria educacional. Trabalha-se sem saber para quê e para quem.

Não é sem razão, que a massa dos profissionais da educação se adequa facilmente aos modismos educacionais, à teoria ou ao método da hora. As políticas emergidas com o advento da Portaria Interministerial de 2007, representa, como política federal, um salto qualitativo enorme, mas insuficiente, se comparada a experiências pedagógicas passadas.

Nesse sentido, o nascente sistema educacional de tempo integral de Manaus, quer pelo projeto educacional, quer pela estrutura que está sendo construída, quer pela incipiente democracia que se insinua no âmbito da gestão das escolas, pode alcançar outros patamares, tais como o da educação integral liberal-democrática, e mesmo, da educação integral politécnica. ${ }^{19}$

$\overline{19}$ As modalidades de educação integral no Brasil são caracterizadas por Maciel, Silva e Frutuoso (2019). 


\subsection{EUIDÊNCIAS DE UMA ALTERNATIUA DE GESTÃO DEMOCRÁTICA PARA A EDUCAÇÃO INTEGRAL}

As características empíricas da gestão democrática das escolas analisadas indicam que elas transitam entre o gerencialismo espontaneísta, ao se postarem a atender as orientações oficiais, as das diversas instituições do terceiro setor e as proposições legais do movimento sindical.

Não se detecta, mesmo no âmbito da legalidade dos princípios educacionais, um movimento voltado para a gestão de processos educativos, que possam buscar, efetivamente, os fins da educação, que: "tem por finalidade o pleno desenvolvimento do educando, seu preparo para o exercício da cidadania e sua qualificação para o trabalho." (BRASIL, 1996).

A elevada taxa de professores, que não conseguiram identificar a metodologia de ensino que utilizam e a teoria que the dá suporte epistemológico, indica o baixo nível de formação teórica, por conseguinte de uma prática pedagógica às cegas, o que implica, dada a vulgarização da autoajuda, do maternalismo familiar, da compaixão religiosa, e mesmo de crenças populares, que a prática pedagógica se sustenta, em grande parte, por saberes tácitos oriundos do cotidiano.

Essa é a razão pela qual se afirmou que questões fundamentais para a gestão como a organização e finalidades do trabalho educativo, do tipo de escola e de educação não fazem parte desse universo desses profissionais, a não ser como como aportes secundários.

Para os gestores, a exemplo do que diz a gestora da EETI-2, os meios transformamse nos fins, tal é a compreensão que têm sobre evasão e repetência. Nas palavras dela:

\footnotetext{
A melhoria da qualidade da educação em Manaus é um desafio que deve ser enfrentado com determinação e coragem, só construiremos uma grande nação, se tivermos um bom sistema de ensino público, que permita a socialização do saber com a população. A questão da qualidade do ensino é uma discussão de muitas décadas, muitas Leis foram criadas no sentido de melhorar o nivel de ensino nas escolas públicas, mas ainda não alcançamos os resultados esperados, que é ter uma escola de qualidade para todos, acabando com a evasão e a repetência. Daí a implantação das escolas de Tempo Integral, como uma das alternativas para a melhoria da qualidade do ensino das escolas públicas. (informação verbal).
}

De um lado, isso é produto das políticas oficiais e, de outro, de um movimento teórico, que contraditoriamente menospreza a teoria, a ciência, o ensino das ciências consolidadas, em nome de uma pluralidade, de uma diversidade, de uma relatividade que, embora importantes, não podem e não devem substituir o fundamental da escola, que é o 
ensino científico, a formação para o trabalho, das formas mais lúdicas às mais laboriosas, e a formação para uma cidadania democrática.

Do lado das políticas oficiais, ainda que as políticas do "Tempo Integral" de 2007 sejam um passo significativo no sentido da recuperação da qualidade do ensino brasileiro pós reforma de 1971, é uma regressão frente experiências pedagógicas, no campo da modalidade de educação integral em tempo integral, como os CIEPs e os CEUs, e muito menos ainda frente a educação integral liberal, na forma como experimentada por Anísio Teixeira. Isso para não se falar da educação integral politécnica, cuja experiência pedagógica mostrou as possibilidades de uma educação integral emancipatória, sob uma perspectiva histórico-crítica e, portanto, não liberal.

No entanto, a liberdade dada pela gestão das escolas para que os professores possam decidir por suas metodologias de ensino, as evidências de decisões colegiadas $163 \%$, para avaliar processo de ensino; $72 \%$, para selecionar livro didático; $72 \%$, para as atividades do turno sociocultural-esportivo), a taxa de sindicalização (26\%), ${ }^{20}$ o processo de adequação física das escolas para atender às especificidades da educação integral, estão a indicar as possibilidades de ultrapassar, pela base, a educação de tempo integral, em busca de formas que, de fato, visem ao desenvolvimento pleno das faculdades humanas.

\section{CONSIDERAÇÕES FINAIS}

Os dados colhidos nas três escolas de Manaus, quando observados à luz das modalidades de educação integral e aos princípios da gestão democrática instituídos pela Lei 9.394/96, e analisados pela ótica do materialismo histórico, trazem à tona elementos conceituais, que possibilitam apreender com mais afinidade a realidade dos processos educativos na escola.

Por pressuposto, para a efetivação da educação integral, genericamente falando, a escola precisa ter estrutura física adequada às múltiplas funções, que esse tipo de educação requer; tem de possuir recursos humanos com formação satisfatória que, por si só, não bastam, há que se encontrar os meios de mobilizá-los para um projeto específico de educação integral; e, finalmente, uma gestão democrática comprometida com um projeto específico de educação integral. Mas que projeto de educação integral, se uma taxa elevada de professores sequer identifica sua metodologia de ensino?

20 Conforme Maciel, Silva e Mourão (2015d). 
Desses pressupostos, levando em consideração os dados colhidos nas três escolas, podem se colocar quatro desafios basilares: superar o espontaneísmo afetivo, driblar o gerencialismo burocrático e afetivo, aplicar os princípios da LDB pela perspectiva do movimento sindical e, por fim, pôr em prática uma gestão democrática superadora da educação integral, sob a forma de tempo integral.

Cada um desses desafios é mais difícil do que outro para ser implementado: o espontaneísmo afetivo viceja, de um lado, pela forte penetração da literatura de autoajuda e das concepções religiosas, reforçadas por inúmeros programas oficiais; de outro, pelo isolamento cada vez maior da ciência. 0 exemplo mais contundente: o movimento "Todos pela Educação"!

0 gerencialismo burocrático e, também, afetivo é o meio pelo qual as políticas governamentais através de suas dezenas de programas imprimem o ritmo de trabalho na escola, para cuja execução, novamente, apela-se ao emocional de seus contingentes humanos, tornando o trabalho cada vez mais intensivo, exaustivo e degradante.

Aplicar os princípios da LDB pela perspectiva do movimento sindical é outro obstáculo a ser superado. E há muitas razões para isso, a primeira delas, pelo fato de a escola está vinculada ao sistema a que o movimento sindical faz, quase sempre, oposição e é visto pelos governantes como inimigo; segunda, porque não raramente os gestores, mesmo eleitos, acabam se alinhando ao sistema do estado; terceira, porque o próprio movimento sindical está estrutural e, como sempre, ideologicamente fragmentado.

Finalmente, pôr em prática uma gestão democrática superadora da educação integral, sob a forma de tempo integral. Pensa-se que a ultrapassagem efetiva, em termos de qualidade educacional, somente será possivel pela superação do tempo integral, senão porque mais não seja um ensino, no qual a discência tem o tempo esticado para o outro turno, sob diversas formas, pelo menos porque há, no Brasil, modalidades, cuja forma e conteúdo, comprovadas experimentalmente, estão à disposição das escolas que se proponham a concretizá-las. Nesse sentido, o caminho a seguir depende da correlação das forças sociais atuantes no interior da escola.

\section{REFERÊNCIAS}

AMAZONAS. Secretaria de Estado da Educação do Estado do Amazonas. Proposta pedagógica das escolas da rede estadual de ensino de educação em tempo integral. In: AMAZONAS. Resolução n 112, de 20 de outubro de 2008. Aprova o Projeto de Escolas de Tempo Integral no Estado do Amazonas e dá outras orientações. Manaus: Conselho Estadual de Educação - CEE/AM, 2008.

ASSIS, R. M. A educação brasileira durante o período militar: a escolarização dos 7 aos 14 anos. Educação em Perspectiva, v. 3, n. 2, p. 320-339, jul./dez. 2012. 
BRASIL. Decreto n. 7.083, de 27 de janeiro de 2010. Dispõe sobre o programa Mais Educação. Diário Oficial da União, Brasília, DF, 28 jan. 2010. Disponível em: http://www.planalto.gov.br/ccivil_03/_ ato2007-2010/2010/decreto/d7083.htm. Acesso em: 23 abr. 2016.

BRASIL. Lei n. 9.394, 20 de dezembro de 1996. Estabelece as diretrizes e bases da educação nacional. Diário Oficial da União, Brasília, DF, 21 dez. 1996. Disponível em: http://www.planalto.gov.br/ccivil_03/ leis/19394.htm. Acesso em: 16 ago. 2016.

BRASIL. Lei n. 10.172, de 9 de janeiro de 2001. Aprova o Plano Nacional de Educação e dá outras providências. Diário Oficial da União, Brasília, DF, 10 jan. 2001. Disponivel em: http://www.planalto.gov.br/ ccivil_03/leis/leis_2001/110172.htm. Acesso em: 16 ago. 2016.

BRASIL. Lei n. 13.005, de 25 de junho de 2014. Dispõe sobre o Plano Nacional de Educação - PNE e dá outras providências. Diário Oficial da União, Brasília, DF, 26 jun. 2014. Disponível em: http://www. planalto.gov.br/ccivil_03/_ato2011-2014/2014/lei/113005.htm. Acesso em: 17 ago. 2016.

BRASIL. Ministério da Educação. Portaria Normativa Interministerial nº-17, de 24 de abril de 2007. Dispõe sobre o Programa Mais Educação. Diário Oficial da União, Brasília, DF, 26 abr. 2007. Disponível em: http://portal.mec.gov.br/arquivos/pdf/mais_educacao.pdf. Acesso em: 16 ago. 2016.

BRASIL. Ministério da Educação. Secretaria de Articulação com os Sistemas de Ensino. Planos de carreira e remuneração: contribuições para a elaboração e a revisão de planos de carreira e remuneração dos profissionais da educação escolar básica pública. Organizado por Sérgio Roberto Gomes de Souza. Brasilia, DF: MEC/SASE, 2016.

BRASIL. Ministério da Educação. Sistema Educacional Brasileiro. Programa Nacional de Fortalecimento dos Conselhos. Conselho escolar, gestão democrática da educação e escolha do diretor. Brasilia, DF: MEC, 2004a.

BRASIL. Programa Nacional de Fortalecimento dos Conselhos. Conselhos escolares: uma estratégia de gestão democrática da educação pública. Brasília, DF: MEC, 2004b.

CAVALIERE, A. M. V. Anísio Teixeira e a educação integral. Paideia, v. 20, n. 46, p. 249-259, maio/ago. 2010. Disponivel em: https://www.scielo.br/pdf/paideia/v20n46/11.pdf. Acesso em: 29 mar. 2016.

CAVALIERE, A. M. V. Educação integral: uma nova identidade para a escola brasileira? Educação \& Sociedade, v. 23, n. 81, p. 247-270, dez. 2002.

CONFEDERAÇÃO NACIONAL DOS TRABALHADORES EM EDUCAÇÃO. Mobilização em defesa do FUNDEB permanente e com mais recursos da União. Brasilia, DF: CNTE, 2019.

CURY, C. R. J. Gestão democrática da educação: exigências e desafios. Revista Brasileira de Política e Administração da Educação, v. 18. n. 2, p. 163-174, jul./dez. 2002. 
FERREIRA, J. N. 0 ensino médio nas escolas de tempo integral. 2012. 92 f. Dissertação (Mestrado em Acadêmico em Educação) - Faculdade de Educação, Universidade Federal do Amazonas, Manaus, 2012.

GRACINDO, R. V. Gestão democrática nos sistemas e na escola. Brasília: UnB, 2007.

JACOMINI, M. A.; PENNA, M. G. 0. Carreira docente e valorização do magistério: condições de trabalho e desenvolvimento profissional. Pro-Posições, v. 27, n. 2, maio/ago. 2016.

MACIEL, A. C.; BRAGA, R. M. Projeto Burareiro: politecnia e educação integral à luz da pedagogia histórico-crítica. In: SANTOS, N. Alinhavos em ciências humanas. Porto Velho: EDUFR0, 2007. p. 59-74.

MACIEL, A. C.; JACOMELI, M. R. M.; BRASILEIRO, T. S. A. Fundamentos da educação integral politécnica: da teoria à prática. Educação \& Sociedade, v. 38, n. 139, p. 473-488, abr./jun. 2017.

MACIEL, A. C. Marx e a politecnia, ou: do princípio educativo ao princípio pedagógico. Revista Exitus, v. 2, n. 2, p. 85-110, 2018.

MACIEL, A. C. 0 projeto original. In: MACIEL, A. C.; BRAGA, R. M.; RANUCCI, A. M. C. Projeto burareiro de educação integral: original. Porto Velho: Temática, 2016. p. 19-40.

MACIEL, A. C.; SILVA, C. A.; MOURÃO, A. R. B. Nota técnica: tabulação do survey multifatorial aplicado à EETI-1. Manaus: [s. n.], 2015a.

MACIEL, A. C.; SILVA, C. A.; MOURÃO, A. R. B. Nota técnica: tabulação do survey multifatorial aplicado à EETl-2. Manaus: [s. n.], 2015b.

MACIEL, A. C.; SILVA, C. A.; MOURÃO, A. R. B. Nota técnica: tabulação do survey multifatorial aplicado à EETI-3. Manaus: [s. n.], 2015c.

MACIEL, A. C.; SILVA, C. A.; MOURÃ0, A. R. B. Nota técnica: tabulação geral do survey multifatorial - EETI-1, EETI-2, EETI-3. Manaus: [s. n.], 2015d.

MACIEL, A. C.; SILVA, C. A.; MOURÃO, A. R. B. Survey multifatorial. Manaus: [s. n.], 2015e.

MACIEL, A. C.; SILVA, C. A.; FRUTUOSO, C. 0 conceito de educação integral e as possibilidades da educação integral politécnica em Manaus. Práxis Educacional, v. 15, n. 32, p. 174-204, abr./jun. 2019.

MACIEL, A. C.; SILVA, C. A. Fundamentos da concepção de educação integral: uma análise das políticas educacionais, entre 1996 e 2014. In: MACIEL, A. C.; GANZELI, P.; COSTA, S. A. Sentidos da educação integral: conceitos, programas e implicações na realidade educacional. Uberlândia, MG: Navegando, 2018. p. 31-47.

MEC; INEP. A situação do ensino no Brasil: limites e avanços. Brasília, DF: INEP, 1997. 
MOREIRA, A. J. de A.; JUNQUEIRA, M. L.; MACIEL, A. C. Centro de educação integral politécnica - CEIP: uma proposta de arquitetura sustentável, educativa e amazônica. In:

MACIEL, A. C. et al. (org.). Gestão da educação integral politécnica: uma proposta para o Brasil, 2. Porto Velho: EDUFRO, 2013. v. 2, p. 113-130.

OLIVEIRA, R. P. de. Da universalização do ensino fundamental ao desafio da qualidade: uma análise histórica. Educ. Soc., v. 28, n. 100, p. 661-690, out. 2007.

PACHECO, R. T. B. 0 espetáculo da educação: os Centros Educacionais Unificados do Município de São Paulo como espaços públicos de lazer. 2009. 280 f. Tese (Doutorado em Educação) - Faculdade de Educação, Universidade de São Paulo, São Paulo, 2009.

PARÊS, E. G. Sistema democrático de relações de trabalho. Brasilia, DF: CNTE, 2014,

RIBEIRO, D. 0 livro dos ClEPs. Rio de Janeiro: Bloch, 1986.

SANCHES, Y. C. de S. A gestão do Centro Educacional Unificado (CEU) da cidade de São Paulo. 2014. 336 f. Tese (Doutorado em Educação) - Faculdade de Educação, Universidade de São Paulo, São Paulo, 2014.

SAVIANI, D. 0 choque teórico da politecnia. Trabalho, Educação e Saúde, v. 1, n. 1, p. 131-152, 2003.

SAVIANI, D. Trabalho e educação: fundamentos ontológicos e históricos. Revista Brasileira de Educação, v. 12, n. 34, p. 152-165, jan./abr. 2007.

SILVA, C. A. 0 sistema público de educação de tempo integral em Manaus e as possibilidades da educação integral politécnica. 2017. 205 f. Dissertação (Mestrado em Educação) - Faculdade de Educação, Universidade Federal de Rondônia, Porto Velho, 2017.

SILVA, G.; SILVA, A. V.; SANTOS, I. M. Concepções de gestão escolar pós-LDB: gerencialismo e a gestão democrática. Revista Retratos da Escola, v. 10, n. 19, p. 533-549, jul./dez. 2016.

SILVA, L. G. A.; ALVES, M. F. Gerencialismo na escola pública: contradições e desafios concernentes à gestão, à autonomia e à organização do trabalho escolar. Revista Brasileira de Poĺtica e Administração da Educação, v. 28, n. 3, p. 665-681, set./dez. 2012.

TEIXEIRA, A. Centro Educacional Carneiro Ribeiro. Revista Brasileira de Estudos Pedagógicos, v. 31, n. 73, p. 78-84, jan./mar. 1959.

TEIXEIRA, A. Plano de construções escolares de Brasilia. Revista Brasileira de Estudos Pedagógicos, v. 35, n. 81, p. 195-199, jan./mar. 1961.

Endereço para correspondência: Avenida Getúlio Vargas, 401, apto 302, Centro, 69020-010, Manaus, Amazonas, Brasil; cintiaadelia.adelia@gmail.com 